\title{
Implementación de técnicas digitales para la documentación arqueológica en la villa romana de Salar (Granada)
}

\section{The Implementation of Digital Techniques for Archaeological Documentation in the Roman Villa of Salar (Granada)}

\author{
Ángela Rosa Henestrosa* \\ Universidad de Granada \\ https:/ / orcid.org/0000-0002-4787-7243 \\ angelarosa98@gmail.com \\ Manuel Moreno Alcaide \\ Universidad de Málaga \\ https:/ / orcid.org/0000-0001-9906-4773 \\ mmorenoalcaide@uma.es
}

\author{
Julio M. Román Punzón \\ Universidad de Granada \\ https:/ / orcid.org/0000-0001-6351-2511 \\ romanp@ugr.es \\ Pablo Ruiz Montes \\ Universidad de Granada \\ https://orcid.org/0000-0002-3595-4184 \\ prmontes@ugr.es
}

Recibido: 19/07/2021; Revisado: 21/11/2021; Aceptado: 09/11/2021

\begin{abstract}
Resumen
La aplicación de técnicas digitales para la documentación gráfica es, cada vez, más habitual en los proyectos de investigación arqueológica. Sin embargo, su implementación se ha realizado, en muchos casos, sin la necesaria reflexión crítica acerca de su utilidad real frente a los sistemas tradicionales, y/o un breve análisis que permita optimizar su uso. En este trabajo, pretendemos ofrecer ciertas evidencias al respecto de la relación entre tiempo, usabilidad y precisión en la aplicación de técnicas fotogramétricas para la representación gráfica en intervenciones arqueológicas a partir de nuestra experiencia en la villa romana de Salar.
\end{abstract}

Palabras clave: Salar, villa romana, fotogrametría, digitalización, arqueología.

\begin{abstract}
The application of digital techniques for graphical documentation is increasingly common in archaeological research projects. Nevertheless, in many cases these digital techniques have been implemented without the necessary critical reflection regarding their real-world usefulness compared with traditional methods, and/or a brief analysis of their optimal use. This article offers evidence
\end{abstract}

*Autora de correspondencia / Corresponding author.

Copyright: (C) 2022 ULPGC. Este es un artículo de acceso abierto distribuido bajo los términos de la licencia Creative Commons Atribución-NoComercial-SinDerivar (by-nc-nd) Spain 3.0. 
Implementación de técnicas digitales para la documentación arqueológica

about the relationship between time, usability and accuracy in the application of photogrammetric techniques to graphical representation in archaeological projects, based upon our experience in the Roman villa of Salar.

Keywords: Salar, Roman Villa, Photogrammetry, Digitization, Archaeology.

\section{LA ARQUEOLOGÍA Y LAS NUEVAS TECNOLOGÍAS ${ }^{1}$}

Son muchas las definiciones que se han asignado a la Arqueología, pero una que podría ser válida es aquella que la señala como la ciencia que estudia las sociedades pasadas, y la relación con su entorno, a partir del análisis de su cultura material. El desarrollo de proyectos de investigación científicos, y la consecuente conservación y puesta en valor de muchos yacimientos arqueológicos, ha generado la demanda de un turismo especializado en este tipo de recursos patrimoniales que está creciendo constantemente desde hace varias décadas (MORENO y SARASIEGO, 2017: 167). Aunque no siempre la arqueología se ha preocupado de la vertiente de la divulgación científica, a partir del siglo xx se empieza a cambiar la antigua concepción academicista de la disciplina, y la arqueología y el turismo se tienden la mano para afrontar las nuevas demandas y necesidades de los ciudadanos, que buscan, de manera masiva, los destinos turísticos con recursos arqueológicos. Es, en este momento, cuando se desarrolla el llamado turismo arqueológico.

La ciencia arqueológica tiene como obligación no sólo la investigación de la cultura material, el establecimiento de hipótesis históricas científicas, sino también la difusión a la sociedad de sus resultados; es ahí donde el turismo puede jugar un papel fundamental como herramienta educativa para todos los visitantes (MORENO y SARASIEGO, 2017: 169). De esta forma, se abre una nueva relación entre arqueología y turismo, rompiendo con la antigua concepción formada por la no cooperación entre ambas disciplinas, y que persigue la "sostenibilidad" de los yacimientos arqueológicos, lo cual debe garantizar la conservación de estos a lo largo del tiempo, para que pueda ser legado en las mejores condiciones a las generaciones futuras. Para poder llevar a cabo esta asociación se necesita de un compromiso firme por parte de las administraciones públicas para la investigación, conservación, puesta en valor de estos bienes patrimoniales, así como fomentar la facilidad del acceso universal a los mismos; por otra parte, el sector privado, que juega un importante papel en la experiencia turística, también es responsable de promocionar destinos y crear ofertas turísticas que motiven al consumidor para visitar este tipo de enclaves patrimoniales. Además, el flujo turístico beneficia al desarrollo local, favoreciendo la creación de empleo, y diversificando y mejorando la economía; incluso, permite, bien gestionado, aumentar la protección de los sitios del entorno, combatiendo de esta forma el expolio o la destrucción de aquellos. Es decir, existe una responsabilidad inherente a trabajar por un equilibrio entre el yacimiento y el visitante, con el fin de preservar la herencia cultural y legarla a generaciones futuras (MORENO y SARASIEGO, 2017: 170).

En este contexto, en la actualidad, la tecnología se ha convertido en algo ligado

1 Este trabajo toma como base el TFG realizado por la primera de los firmantes, titulado «Aplicación práctica de técnica digital de restitución (SfM) en Arqueología. La estancia abovedada (CE-03) de la villa romana de Salar (Granada) », defendido en la Universidad de Granada, curso 2019-2020. 
a nuestra propia naturaleza, de tal modo que la facilidad para acceder a la misma ha supuesto un cambio en nuestra forma de vida, comunicación y relación con el entorno. Uno de los ámbitos tecnológicos que han sufrido una mayor evolución han sido las conocidas como Tecnologías de la Información y Comunicación (TIC), que son entendidas como dispositivos tecnológicos (hardware y software) que permiten editar, producir, almacenar, intercambiar y transmitir datos entre diferentes sistemas de información que cuentan con protocolos comunes (CEREZO y Guevara, 2015). De esta forma, ligado al aumento de las TIC, todos los sectores, en consecuencia, tuvieron que adaptarse a estas nuevas tecnologías irrumpiendo, entre ellos, los vinculados a la actividad turística y patrimonial. Es en este contexto cuando, en el año 2016, la UNESCO presentó su «Agenda 2030 de las Naciones Unidas para el Desarrollo Sostenible», ${ }^{2}$ donde:

Se reconoce la importancia de aprovechar plenamente [...] las Tecnologías de Información y Comunicación (TIC) para el desarrollo sostenible, así como la necesidad de fortalecer las capacidades, habilidades y conocimientos humanos incluyendo mediante una educación de calidad para todos a lo largo de la vida.

Por otro lado, es a inicios del siglo XXI cuando se produce un auténtico desarrollo de las conocidas como «Humanidades Digitales» (que, no obstante, tienen su origen a finales de los años cuarenta del siglo $x x$, con los trabajos de Roberto Busa y el desarrollo de la conocida como «Humanities Computing»), entendidas como el conjunto de herramientas tecnológicas computacionales utilizadas para avanzar en el conocimiento y difusión de las Humanidades, y generar y divulgar conocimiento en plataformas digitales. Documentos clave, como la obra colectiva "A companion to Digital Humanities» (SCHREIBMAN et al., eds., 2004), sentaron las bases de la necesaria reflexión teórica en torno a esta auténtica revolución en las Ciencias Humanas.

Debido a la rápida evolución tecnológica y la paralela creación de numerosos proyectos dedicados a la investigación, difusión, puesta en valor, documentación, etc., de distintos elementos del patrimonio cultural, era necesario elaborar una serie de principios que asegurasen la realización de trabajos con una metodología adecuada y técnicamente rigurosos. Surgen, así, documentos de alcance internacional, como la llamada Carta de Londres (2006), con el objetivo de garantizar el rigor metodológico de la visualización por computadora como medio de investigación y comunicación del patrimonio cultural, y, derivado de aquel, y para el caso que nos ocupa, la redacción de los Principios de Sevilla. Principios internacionales de la Arqueología Virtual (LóPEZ-MENCHERO y GRANDE, 2011: 71-75), que suponen aumentar las condiciones de aplicabilidad de la Carta de Londres, de cara a su mejor implantación en el campo específico del patrimonio arqueológico, al mismo tiempo que se ofrecen algunas recomendaciones nuevas que toman en consideración la peculiar naturaleza del patrimonio arqueológico con respecto al patrimonio cultural. Así, se desarrollan distintos principios que deben sentar las bases de cualquier proyecto arqueológico que haga uso de las nuevas tecnologías: Interdisciplinariedad, Finalidad, Complementariedad, Autenticidad, Rigurosidad Histórica, Eficiencia, Transparencia Científica y, por último, Formación y Evaluación (LópEz-MENCHERO, 2011: 66-68).

De esta forma, una de las finalidades del uso de las NNTT en la Arqueología

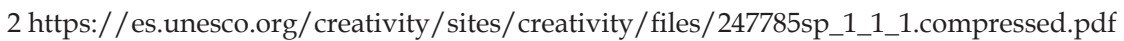


es la documentación del registro arqueológico, que se configura como un aspecto fundamental debido a la conocida y necesaria naturaleza destructiva del método científico propio de dicha disciplina (CARANDINI 1997: 18-19). Cada unidad estratigráfica, asociada a su contexto y artefactos, una vez excavada, no se puede volver a recuperar. Debido, por tanto, a su carácter informativo, único e irrecuperable, una documentación rigurosa adquiere un significado decisivo dentro de la arqueología. Y es en este contexto en el cual la tecnología asociada a la fotogrametría digital, como técnica de registro patrimonial, se torna indispensable para una escrupulosa documentación del registro arqueológico, maximizando la información recuperada y permitiendo una posterior restitución de la secuencia excavada, que, finalmente, permita interpretar la evidencia material y generar un conocimiento científico riguroso y objetivo.

Efectivamente, las técnicas de documentación también se han visto sumergidas en este crecimiento tecnológico, donde se pasa de la utilización de técnicas convencionales, como el dibujo arqueológico a mano, a técnicas digitales de documentación, como el escáner láser, que surge en la mitad del siglo Xx, o la propia fotogrametría digital. En todo caso, y atendiendo a ese principio de Complementariedad señalado en los Principios de Sevilla, esto no quiere decir que la visualización asistida por ordenador en el campo de la gestión integral del patrimonio arqueológico sea considerada como sustitutiva de otros instrumentos de gestión más clásicos, pero igualmente eficaces (SOCIEDAD ESPAÑOLA DE Arqueología Virtual -SEAV-).

La fotogrametría digital, técnica de la que trataremos en este trabajo, dispone de un conjunto de programas informáticos de bajo coste, e incluso gratuitos, lo que unido a la disponibilidad de constantes mejoras y abaratamiento de los equipos informáticos y fotográficos, ha fomentado e impulsado su uso cada vez más generalizado, convirtiéndola, de este modo, en una herramienta fundamental para la precisa documentación geométrica y estudio de yacimientos y objetos arquitectónicos (APARICIO et al., 2017).

Por todo esto, conscientes de la importancia de este creciente proceso en la arqueología actual, creemos irrenunciable su aplicación en cualquier proyecto de investigación arqueológica, como el que desarrollamos en la villa romana de Salar. Así, desde el año 2016, venimos empleando la fotogrametría digital como técnica de documentación gráfica en nuestro yacimiento, utilizando para ello el software profesional Agisoft Photoscan (y desde 2019, su versión actualizada, Metashape). Pero dicha utilización ha sido precedida por un proceso de reflexión que pretendía analizar el uso de estas nuevas tecnologías, que habitualmente superan, en cuanto a su potencial y utilidad, las necesidades de la propia Arqueología. Entendemos que es importante, para optimizar su aplicación en la documentación gráfica arqueológica, comprobar si es factible aprovechar todo su potencial, habida cuenta de la relación entre las necesidades y coste del hardware, el tiempo de elaboración y la calidad del resultado obtenido.

Con ese objetivo, decidimos realizar una serie de pruebas con esta técnica de documentación fotogramétrica en un ámbito de nuestro propio yacimiento, el CE-03 de la villa romana de Salar, conocido como la «estancia abovedada» (Moreno et al., 2019a; 2019b), con el fin de alcanzar los mejores y más óptimos resultados para nuestro registro arqueológico, creando, de este modo, un marco metodológico para la generación de modelos fotogramétricos y, posteriormente, la creación de ortofotografías y ortomosaico; asimismo, pretendíamos comprobar 
si el modelo 3D generado, con la calidad y precisión adecuada, permitía el dibujo arqueológico digital sobre el mismo modelo, complementando o sustituyendo el tradicional dibujo arqueológico manual, que al utilizar medios físicos (plomada, cintas métricas, flexómetro) parece algo menos preciso que el trazado directo sobre modelos fotogramétricos.

Además de las ventajas que ofrece esta técnica fotogramétrica para la propia arqueología, éstas se pueden derivar también a contextos como el dela conservación del patrimonio, tanto mueble como inmueble, debido al carácter perecedero de dichos bienes, y a su continua exposición a diversos factores «agresivos», ya sean humanos, climáticos, etc. Esto hace que, con el transcurso del tiempo, y/o por unas inadecuadas condiciones de conservación, se vaya perdiendo información valiosa y elementos de juicio, haciendo así difícil las posibles interpretaciones futuras. Además, debido al creciente interés entre la población con respecto al patrimonio, su conocimiento y preservación, los enclaves arqueológicos son cada vez más solicitados como producto turístico cultural y, por lo tanto, se encuentran más expuestos al deterioro por parte de la afluencia de visitantes. Así, la progresiva puesta en valor de los yacimientos arqueológicos, unido al desarrollo de proyectos de investigación en este ámbito, ha generado una mayor demanda del llamado turismo arqueológico, que está creciendo constantemente desde hace varias décadas (Moreno y SARIEGO, 2017: 167).

Por todo esto, el uso de las nuevas tecnologías resulta vital, y en nuestro caso, para el registro arqueológico, el método de restitución fotogramétrica ofrece grandes resultados en términos de detalle y precisión de la documentación arqueológica generada, por lo cual supone, no una alternativa a la hora de la reproducción del patrimonio, sino una necesidad inevitable.

Como hemos expuesto anteriormente, la fotogrametría es una técnica que ofrece grandes ventajas a la hora de la documentación debido, principalmente, a su rapidez, su relativo bajo coste con respecto a otras técnicas y la calidad en los modelos que se obtienen. Teniendo en cuenta esto, parecería adecuado aplicar esta técnica de restitución a cualquier proyecto arqueológico que quiera contar con una buena y precisa documentación gráfica, como es el caso de la villa romana de Salar. Sin embargo, si no se posee un buen conocimiento del funcionamiento y los requerimientos técnicos de algunos de los programas informáticos habitualmente utilizados para generar modelos fotogramétricos, se corre el riesgo de perder eficiencia, pues no siempre la aplicación de la máxima calidad será recomendable, si atendemos a las necesidades reales del trabajo arqueológico, al precio del equipo necesario para su generación, y al tiempo de procesado. De esta forma, entendíamos que era fundamental comenzar por generar un protocolo que optimizase la relación calidad-tiempo-coste en nuestros trabajos arqueológicos.

\section{LA VILLA ROMANA DE SALAR COMO CASO DE ESTUDIO}

\subsection{Contexto geográfico e histórico-arqueológico}

Salar es una localidad que se encuentra en el Poniente Granadino (Fig. 1), perteneciente a la comarca de Loja. Por su parte, la villa romana de Salar se localiza junto a la actual autovía A-92, que cruza transversalmente toda la Vega de Granada, y que fosiliza la antigua vía natural que, desde época prehistórica, 
conecta las tierras granadinas, hacia el Oeste, con el Valle del Guadalquivir a través de la depresión de Antequera, y hacia el Este, con el Sureste Peninsular. Además, se ubica en el territorio llano que conforma la ribera del río Salar, cuyos fértiles suelos favorecen el desarrollo de las actividades agrícolas.

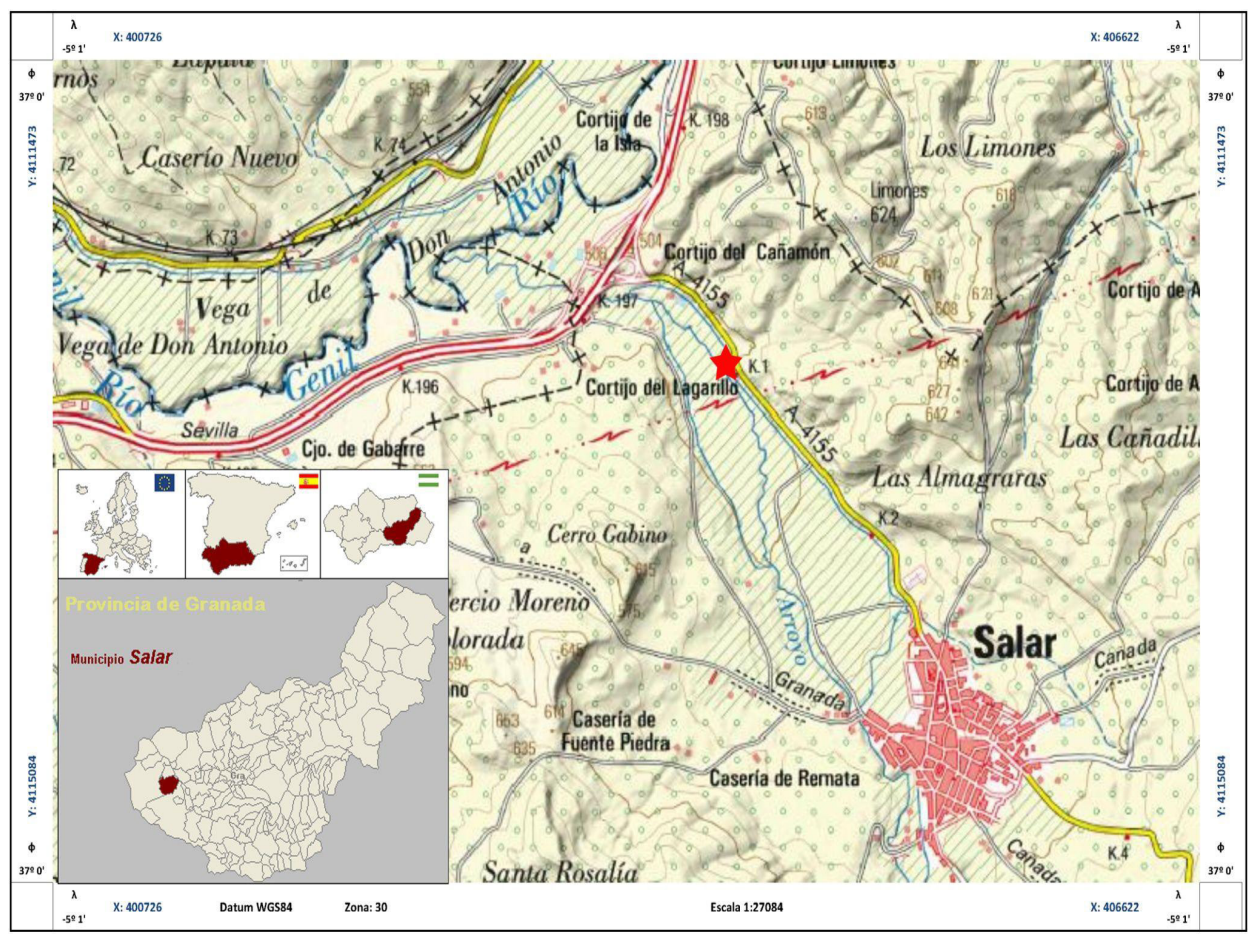

Figura 1. Localización del T.M de Salar y la villa romana (estrella roja) (elaboración propia, a partir del MTN 1:25.000 IGN y http://193.147.167.77/index.php/ Archivo:Salar_(Granada).png)

En noviembre del 2004, y gracias a los movimientos de tierra iniciados para instalar una estación depuradora de aguas residuales, aparecieron numerosos restos arqueológicos tanto materiales como estructurales de época romana. Tras la paralización de las obras por parte de la Junta de Andalucía, se llevaron a cabo varias intervenciones arqueológicas puntuales, entre 2006 y 2007, que confirmaron la existencia de una villa romana de época altoimperial, que fue sepultada por depósitos aluviales y rellenos agrícolas.

De este modo, una vez desechada la continuación del proyecto de EDAR, se concluyó la necesidad de realizar una intervención en extensión que sacase a la luz los restos de la villa identificada. Así, entre los años 2011 y 2013, la Diputación Provincial de Granada financió los trabajos arqueológicos en la zona afectada por los mencionados movimientos de tierra, con objeto de acometer la conservación y puesta en valor de los restos arqueológicos existentes. Se llevó a cabo la excavación, limpieza y consolidación de todos los restos arqueológicos, el vallado del solar, la documentación planimétrica y topográfica, el escaneo láser 3D y la colocación 
de accesos para el visitante, concluyendo con la posterior elaboración de una guía divulgativa (GONZÁLEZ y El AMRANI, 2013).

En resumen, con estas intervenciones se completó la excavación en extensión de un sector de la pars urbana de una lujosa villa romana, presidida por un gran triclinium coronado por una fuente monumental, a modo de ninfeo. También se identificó parte del peristilo y, por extensión, del ambulacrum oriental que daría acceso al triclinium. Algunas estancias que se distribuían en torno a este patio porticado, también fueron parcialmente exhumadas.

Después de un periodo de abandono de la villa, en el año 2016 se retomaron las excavaciones arqueológicas, dirigidas, hasta hoy, por un equipo de investigación universitario, cuyos miembros pertenecen a los Dptos. de Prehistoria y Arqueología e Historia Medieval y CCTTHH, de la Universidad de Granada, así como al Dpto. de Ciencias Históricas de la Universidad de Málaga.

Durante estos últimos 5 años, ha aumentado considerablemente el magro conocimiento que se poseía de la villa romana de Salar, no solo por el aumento del espacio excavado de su pars urbana, sino por la precisa investigación arqueológica que han desarrollado sus excavadores, ejemplificada en la numerosa bibliografía generada en ese corto periodo de tiempo. Dicha actividad arqueológica, sustanciada en 5 campañas arqueológicas estivales, se ha centrado, fundamentalmente, en la conocida como zona B (para distinguirla de la Zona A, la musealizada en el año 2013), un área ubicada en el sector suroccidental de la villa romana, en la que se han identificado, parcialmente, el pasillo peristilado occidental, parte del pasillo septentrional, el tercio oeste del viridarium, así como tres estancias abiertas a dicho ambulacro occidental. Destacan, entre todos los hallazgos, los mosaicos que solan todas las estancias señaladas, siendo particularmente sobresaliente el del pasillo occidental, que muestra varias escenas de cacería, de excelente diseño y conservación, constituyendo un conjunto único en toda la península ibérica (FERnÁndez et al., 2019; Moreno et al., 2021; Román et al., 2021), o su conjunto escultórico, compuesto actualmente por tres pequeñas estatuas femeninas, más concretamente, dos ninfas (venera y púdica) y una venus de tipo capitolino (LozA et al., 2021).

\subsection{Metodología de trabajo}

En todo proceso fotogramétrico se han de seguir una serie de pasos, que conllevan, en menor o mayor medida, la intervención humana. Creemos necesario por esto, y de forma previa a la explicación metodológica de nuestro caso de estudio, tener en cuenta las consideraciones que expondremos en este apartado.

La obtención de unos buenos resultados depende, en gran parte, de una adecuada toma de datos, que constituye uno de los puntos básicos en todo el proceso. Para ello, es necesario realizar un análisis previo que permita acercarnos al objeto a digitalizar, y poder, así, plantear una adecuada estrategia de captura que contemple desde los materiales que vamos a utilizar, como pértigas, drones, etc., hasta el contexto del elemento a fotografiar, material, fragilidad, si se puede girar, voltear o está fijo, etc. Todo este estudio previo servirá como garantía de calidad a la hora de la resolución final del modelo.

Lo importante en la toma de datos es realizar capturas fotográficas regulares, que cubran por completo al objeto para evitar problemas posteriores de solape. 
Con esto nos referimos a que dos imágenes tienen que tener, al menos, la mitad de coincidencia entre una y otra para que, posteriormente, el programa que utilicemos encuentre puntos comunes (Figs. 2 y 3). Además del solape necesario para el procesamiento del modelo fotogramétrico, es esencial el control de las luces, ya que esto es determinante para la textura del modelo debido a que puede afectar a los colores, tonos y sombras, así como a la posterior creación de la malla por el software fotogramétrico. Hay casos en los que la luz puede ser controlada, porque nos encontramos en espacios de trabajo donde la iluminación procede de focos; sin embargo, y adelantando cuestiones sobre nuestro caso de estudio, las luces son naturales y hay que lidiar con estos problemas.

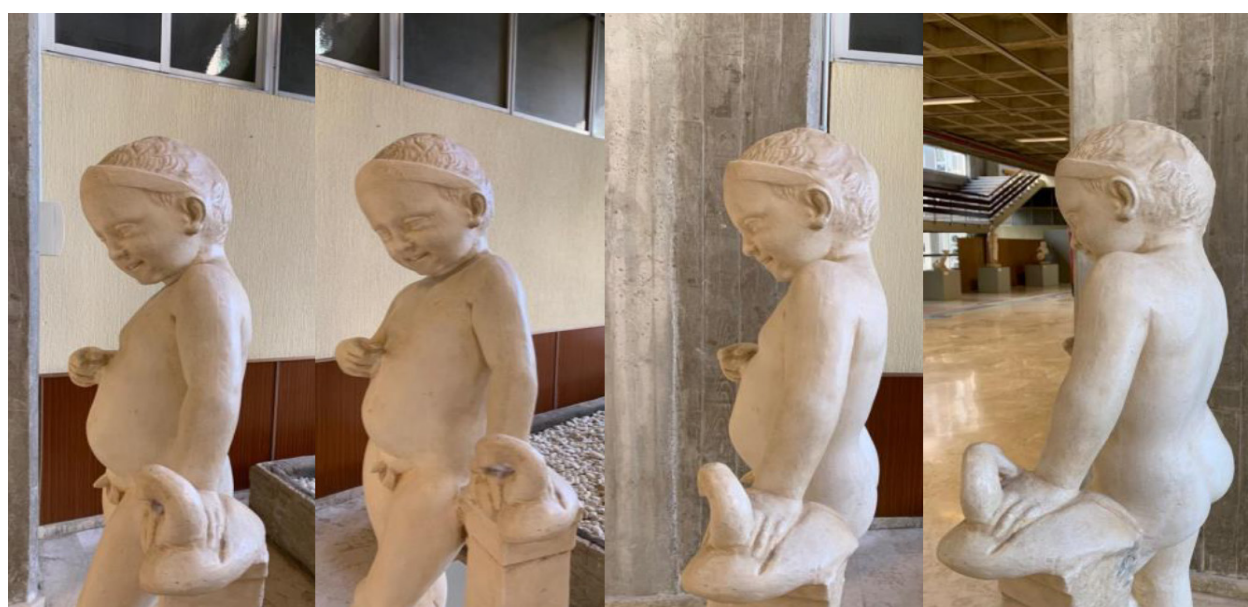

Figura 2. Ejemplo de tomas de fotografías. Elaboración propia.

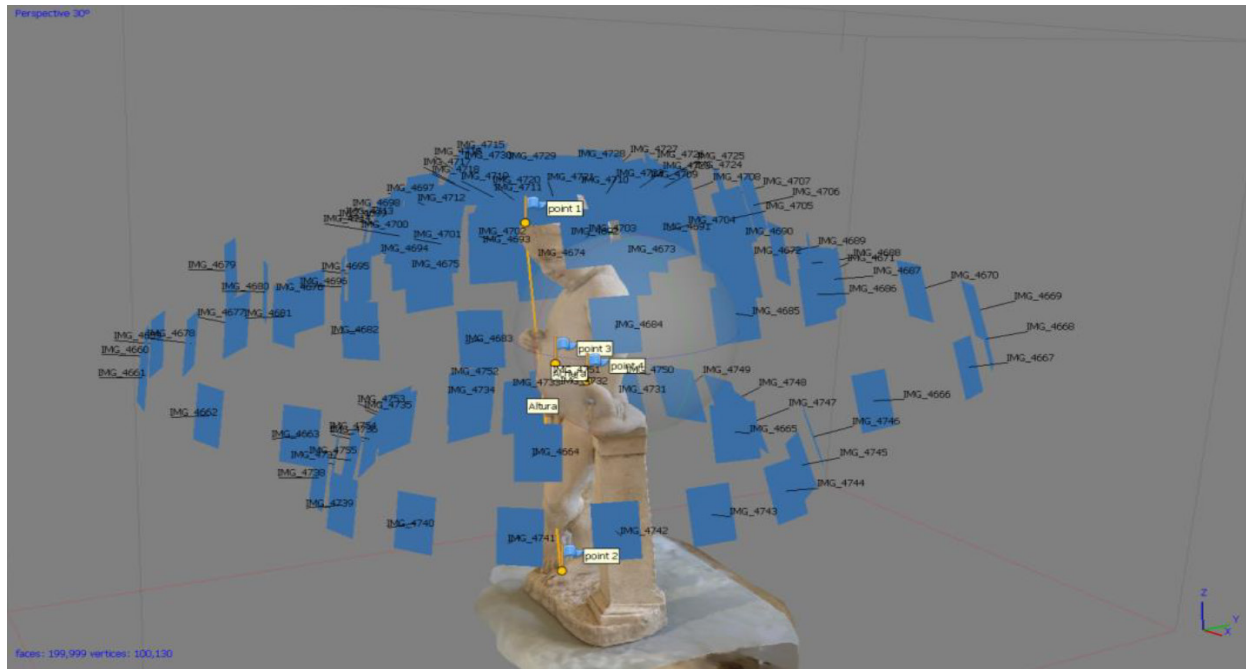

Figura 3. Ejemplo sobre la disposición de las cámaras alrededor del objeto.

Elaboración propia. 
Las capturas fotográficas para un modelo fotogramétrico pueden realizarse con dispositivos que van desde smartphones hasta cámaras con gran calidad que disponen de precisos sensores. Aunque no se disponga de una cámara de alta gama, las restituciones fotogramétricas pueden ser de una calidad y detalles óptimos si sabemos cómo sacarle el máximo partido a nuestro dispositivo. De esta forma, es necesario conocer todos los componentes de nuestra cámara y ajustar sus parámetros para potenciar todo lo posible sus capacidades en las capturas.

Por último, dentro de este apartado general, es necesario señalar la importancia que tienen la organización en carpetas del proyecto, debido, especialmente, a la solución posterior de posibles problemas en los modelos. En el apartado siguiente veremos cuál ha sido la organización en nuestro caso de estudio.

Respecto al ámbito que nos ocupa, la conocida como «estancia abovedada» o CE-03, fue someramente excavada entre los años 2011 y 2013, por lo cual ha sido durante las últimas campañas arqueológicas (Fig. 4), y más concretamente, en las de 2016 (Fig. 5), 2019 y 2020, cuando se ha finalizado su excavación. Con unas medidas aproximadas de 6 por $6 \mathrm{~m}$, este ámbito poseía gran interés debido a su planta especial, con varios retranqueos, así como a la posible cubierta abovedada que debió presentar, habida cuenta del hallazgo de gran cantidad de piezas tubulares cerámicas, más conocidas en la bibliografía especializada como tubi fittili.

Se trata de una estancia de prestigio, con paramentos de opus vittatum mixtum, que, sin conocer aún su funcionalidad (queda parte de este ámbito por descubrir, ya que se adentra por debajo del perfil de la zona A del yacimiento), evidencia su singularidad, a partir de su planta arquitectónica especial, así como por su cubierta abovedada, formada por la anexión de decenas de hiladas formadas por centenares de tubi fittili, técnica constructiva muy exclusiva, con pocos ejemplos peninsulares, y de procedencia norteafricana (MORENO et al., 2019b).

En la campaña arqueológica del año 2019, se pudo comprobar que la estancia estuvo solada, como el resto de los espacios hasta ahora identificados en la villa, con un pavimento de opus tesselatum, en este caso, con motivos geométricos, del cual se documentan unos escasos restos adosados a los muros perimetrales de la estancia. Sería durante la ocupación tardoantigua de este espacio cuando se destruye el mosaico, desapareciendo, incluso, la mayoría del nivel de preparación de mortero de cal sobre el que se disponían las teselas. La evidencia de esta mencionada destrucción, se ve reflejada, por un lado, en la cantidad de pequeños agujeros que muestra el suelo, de difícil interpretación, pero que hay que relacionar con las actividades domésticas que se debieron llevar a cabo en ese momento, y por otro, un estrato de pequeño grosor, que apareció en algunos puntos sobre el suelo agujereado, con gran cantidad de cerámica común, fechada en la primera mitad del s. VI d. C. 
Implementación de técnicas digitales para la documentación arqueológica

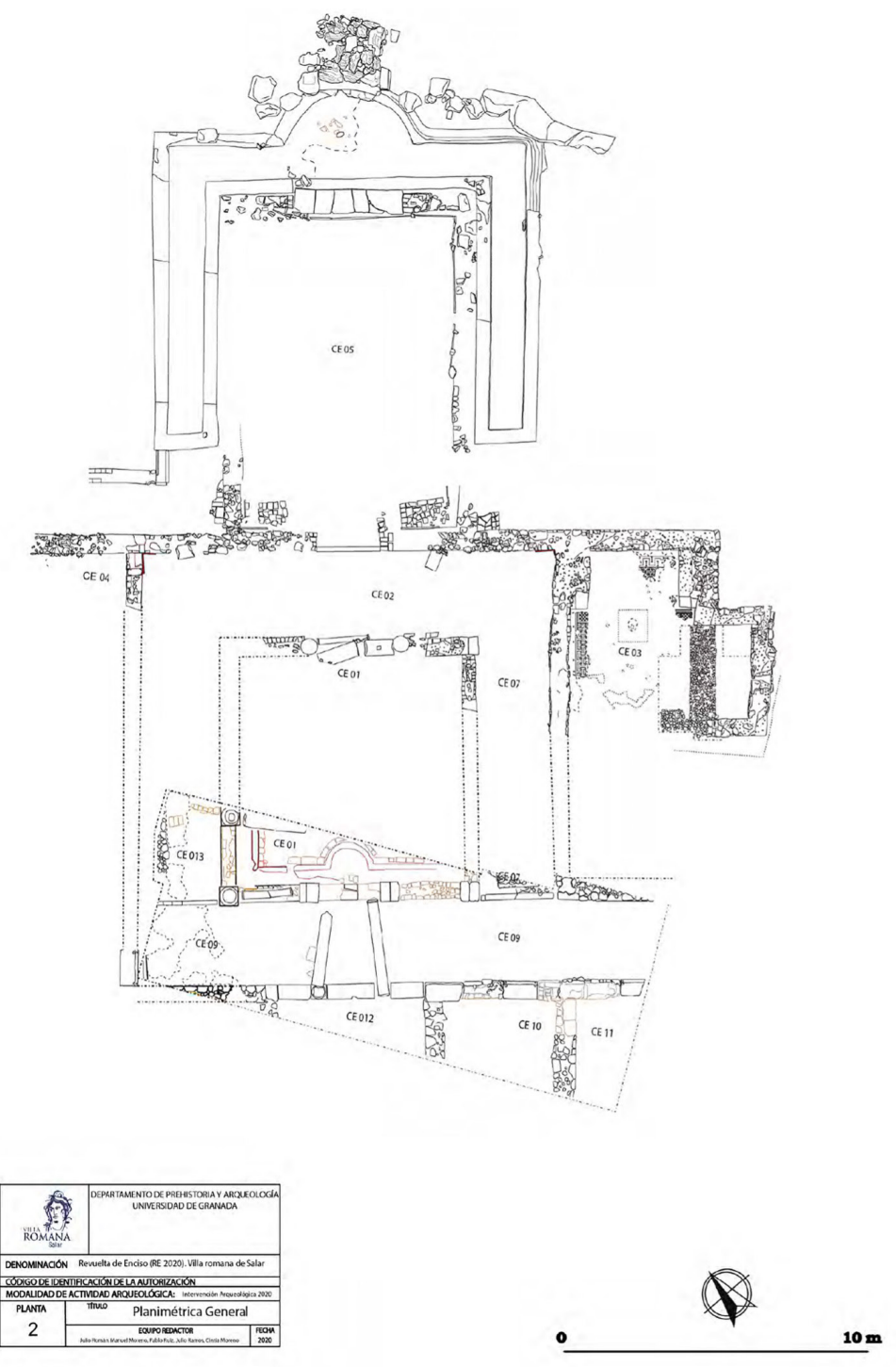

Figura 4. Planta de la excavación, año 2020. Autor: PGI Villa romana de Salar. 


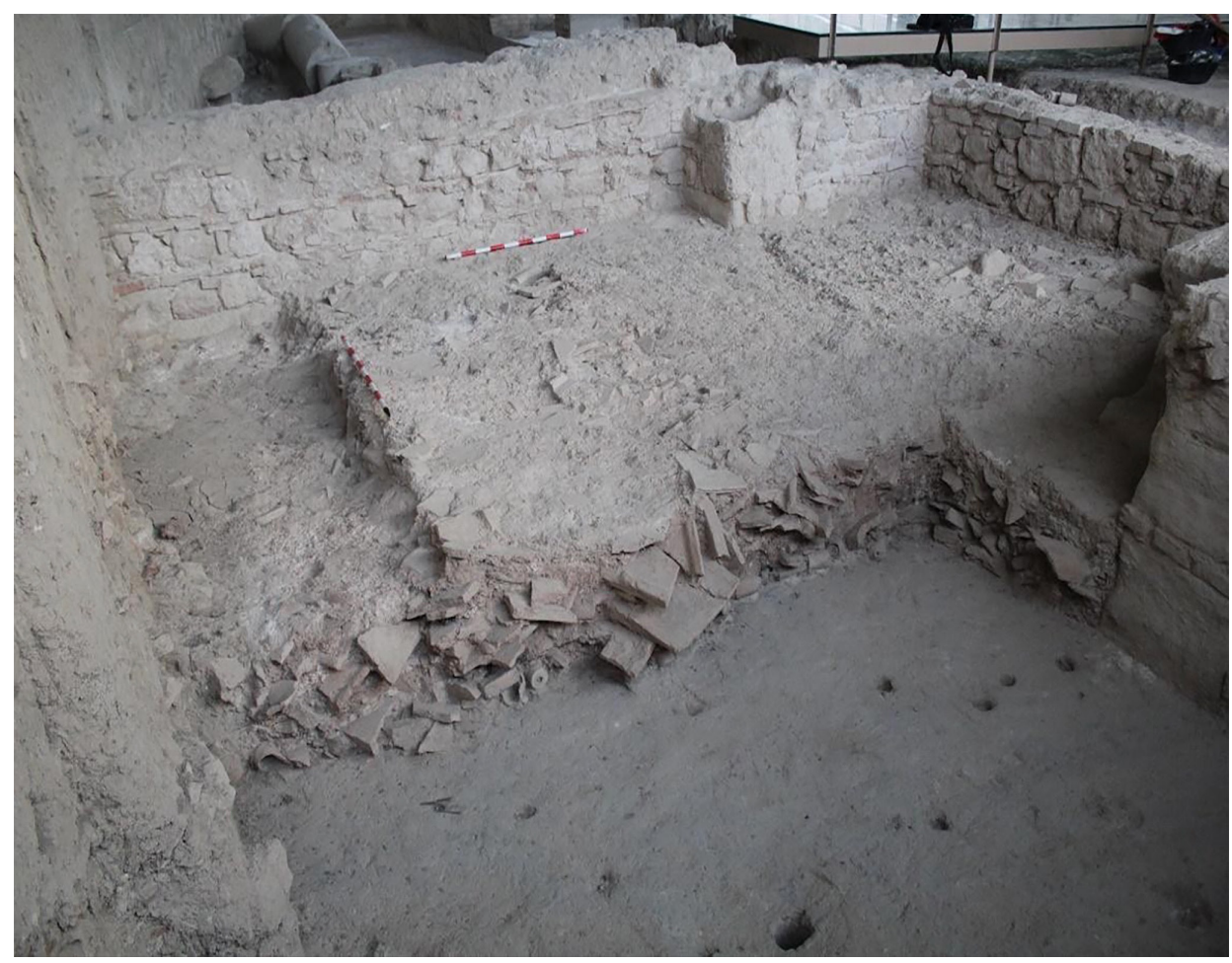

Figura 5. Estado final de la excavación del CE-03, en 2016.

Autor: PGI Villa romana de Salar.

Hay que destacar, igualmente, el excelente estado de conservación de la estructura de tubi que conformó la cubierta abovedada con que contó este ámbito, habiéndose recuperado, no solo cientos de piezas, engarzadas y conformando las diferentes hiladas que las componen, con distintas direcciones, sino también, y este aspecto creemos que es inédito hasta hoy en la arquitectura romana conocida, la clave de bóveda (Fig. 6) de este sistema constructivo.

El tipo de objeto al que nos enfrentamos, en este caso, es un área construida, de mediano tamaño, concretamente, de $6 \times 6 \mathrm{~m}$. Teniendo en cuenta esto, el objetivo focal que hemos utilizado en nuestra cámara (Canon EOS 750D) es uno de $35 \mathrm{~mm}$, que permite realizar fotografías con un ángulo de visión abierto. Los parámetros de la cámara varían según las unidades y el tipo de luz en el momento de la toma, aunque de forma general tienen un ISO bajo. El resto de parámetros (apertura y velocidad) dependen de la luz y del momento concreto de la toma. Estos parámetros quedaron recogidos en tablas diferenciadas por UE en el dicho Trabajo de Fin de Grado.

Asimismo, como técnica de barrido para la captura fotográfica se han utilizado dos de ellas, de manera alternativa: una técnica que se usa para superficies planas, mediante los solapes laterales, y superiores e inferiores, a modo de mosaico (CHARQUero, 2016: 144), y otra, que consiste en el solape de fotos en forma circular (Fig. 7), que rodean al sector a documentar. 


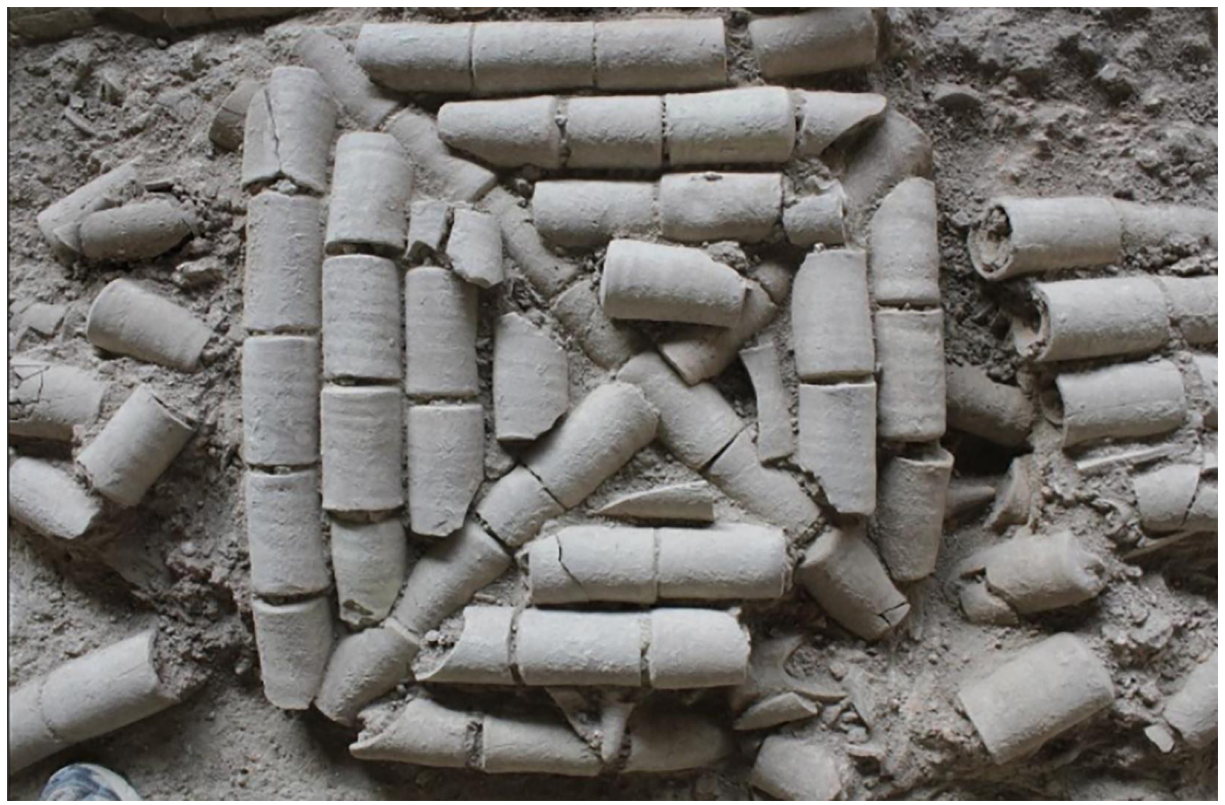

Figura 6. Clave de bóveda de la cubierta del ámbito CE-03. Autor: PGI Villa romana de Salar.

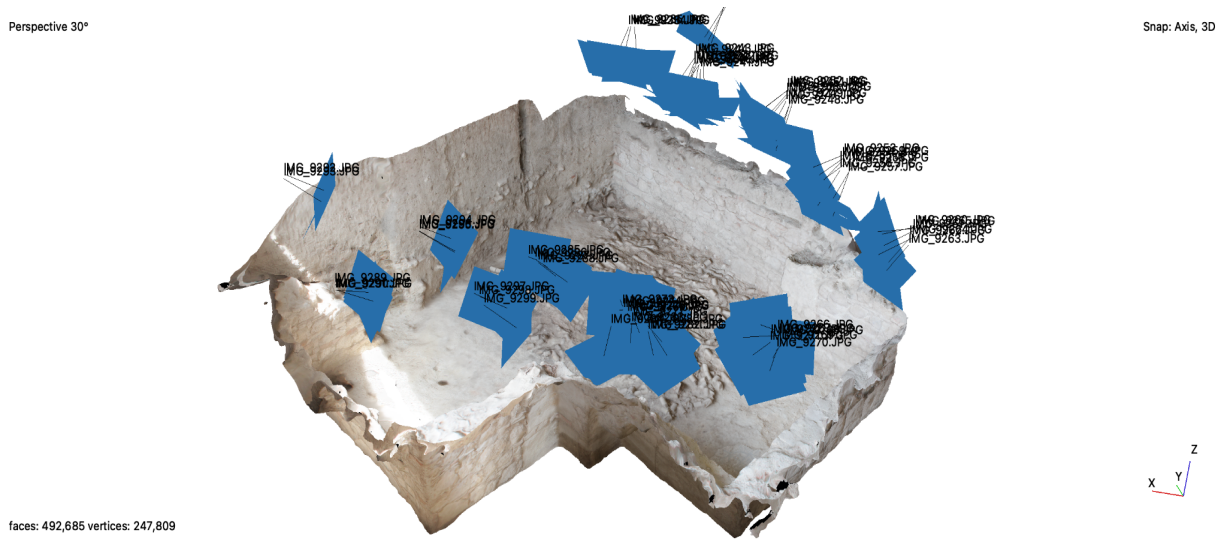

Figura 7. Estrategia de captura, solape circular. Elaboración propia.

Es muy importante evitar en mayor medida el exceso de luz y sombras; sin embargo, en este sector, al ubicarse en el interior del espacio cubierto Zona A, el cual, además, posee un acristalamiento lateral, a determinadas horas del día se hacía muy complicado solventar adecuadamente el problema de los diferenciales de luminosidad -algunos, muy acentuados- en el área a documentar (Fig. 8). En este caso, los modelos que presentaban problemas de iluminación debieron ser 
tratados, posteriormente, con un software distinto, en este caso, Adobe Photoshop, con el objeto de rectificar, en la medida de lo posible, dichos diferenciales.

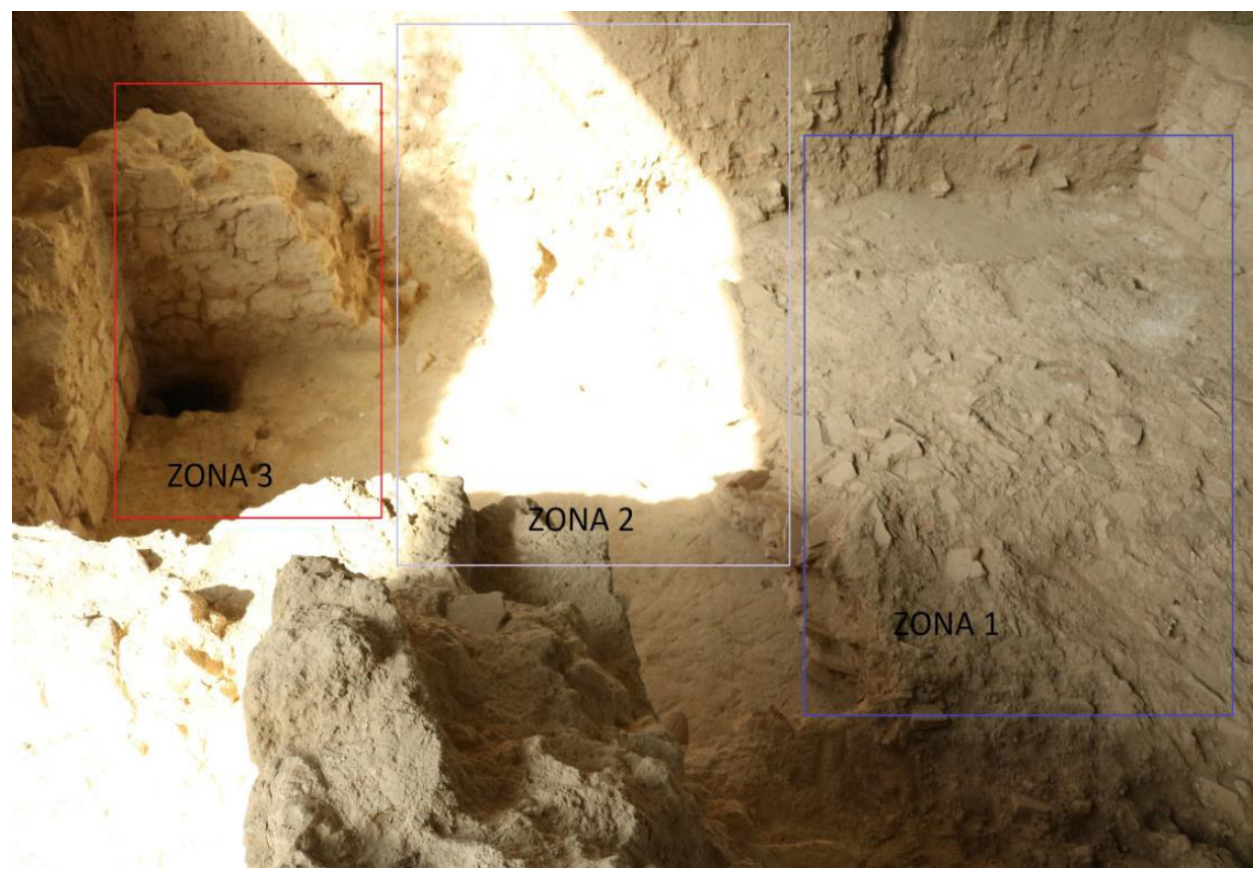

Figura 8. Fotografía del sondeo CE-03, con evidentes problemas de luminosidad diferencial. Autor: PGI Villa romana de Salar.

Asimismo, las capturas fotográficas se realizaron por cada una de las nuevas unidades que fueron identificándose en la excavación en años distintos, 2016 y 2019. Cada una de las mismas está documentada fotográficamente por una media de 30 fotografías, en formato JPEG, a excepción del modelo final que veremos en los resultados de este trabajo.

Previamente a la creación del modelo es esencial que dispongamos de una organización de carpetas que contengan la información ordenada, como hemos comentado con anterioridad. Los datos se dispondrán en dos carpetas principales distintas, una del año 2016 y otra del año 2019. Dentro de la carpeta de fotogrametría, incluimos otras con las distintas unidades estratigráficas, con un número de referencia para conocer su orden, y dentro de estas, crearemos dos carpetas, una con las fotos de ese sondeo y otra con el modelo fotogramétrico. El hecho previo de ordenar las carpetas no solo responde a una lógica organizativa, sino que, al crear un modelo, se genera una ruta que relaciona a éste con las fotografías. Así, en el supuesto caso de que dichas fotos, posteriormente, cambiasen de lugar, se produciría un error en el modelo y deberíamos modificar la ruta de las imágenes que redirigen a las mismas. Por esto, es importante planificar la organización de las carpetas e imágenes antes de proceder a la restitución. 
Con el auge de la fotogrametría, en los últimos años ha aumentado la creación de softwares específicos para la restitución fotogramétrica, $y$, consecuentemente, han adquirido un gran interés en diferentes campos del patrimonio cultural, y sobre todo, en la rápida y rigurosa documentación arqueológica (ANGAS, 2019: 143). En nuestro caso, hemos optado por la utilización de Agisoft Metashape 1.5.3. Se trata de un producto de software independiente que realiza el proceso fotogramétrico de imágenes digitales y genera datos espaciales 3D para ser utilizados en aplicaciones GIS, documentación del patrimonio cultural y producción de efectos visuales, entre otros usos. Su interfaz dispone de configuraciones personalizadas que van desde la selección de temas o apariencia, hasta la personalización de atajos que permiten trabajar de forma más rápida con el teclado. La vista de trabajo principal está formada por una esfera en el centro de trabajo de la interfaz, que crea un espacio de tres dimensiones que ayudará a mover el modelo en dichas direcciones.

En cuanto al proceso que se lleva a cabo, está formado por varios pasos, siendo el primero de ellos la Alineación, que consiste en el reconocimiento individual, en cada una de las fotos, de los puntos clave que la contienen y que son coincidentes entre ellas. Posteriormente, se crea la Nube de Puntos Densa mediante un proceso igual que el anterior, pero como una nube de puntos mayor; este paso requiere de mucha más potencia en nuestro equipo informático. Después de la generación de esta nube se crea la Malla, formada por triángulos, donde se pasa de un objeto formado por muchos cientos de puntos a un objeto sólido con geometría. Por último, se genera la Textura, realizándose tanto por color de vértice como por la textura fotorrealista, con gran calidad, a partir de las fotografías.

Llegados a este punto es importante hacer una aclaración acerca del flujo de trabajo utilizado. Somos conscientes de que una de las novedades de la versión 1.5, denominada Metashape, del software de Agisoft (lanzada al mercado en marzo de 2019), frente a la anterior versión, llamada Photoscan, es el poder utilizar la generación de la malla directamente con mapas de profundidad, saltándose el paso de la generación de la nube de puntos densa, lo cual permite disminuir considerablemente el tiempo de procesado. No obstante, aún son muchos los usuarios de la versión anterior de este software de procesado fotogramétrico de Agisoft, no habiendo actualizado todavía a la «reciente» versión 1.5. Y como aquella todavía no permitía trabajar directamente con mapas de profundidad, sino que obligaba a hacer la nube de puntos densa primeramente, es por ello que hemos preferido usar el flujo con dicho procedimiento con el objeto de que nuestro «experimento» fuese útil a todo aquel que no tuviese la actualización Metashape. En todo caso, ya veremos que el punto crítico del procesado de los modelos fotogramétricos está en la generación de la malla, no en la nube de puntos densa, de tal modo que el uso de uno u otro procedimiento previo a la generación de dicha malla no determina el éxito final de la creación del modelo 3D.

En todo trabajo fotogramétrico es importante seleccionar, entre las posibilidades que ofrece el software, las propiedades que asignaremos al procesado del modelo. En nuestro caso, se optó, inicialmente, por seleccionar una Calidad Alta en la Alineación de puntos clave, y una Calidad Media tanto para la generación de la Nube de Puntos Densa (Tabla 1) como para la elaboración de la Malla. Posteriormente, justificaremos esta selección. 
TABLA 1

Propiedades seleccionadas para la generación del modelo fotogramétrico de la Unidad Estratigráfica 1174

\begin{tabular}{|c|c|c|}
\hline \multirow{4}{*}{1774} & PROCESO & PRECISIÓN/CALIDAD \\
\hline & $\begin{array}{c}\text { Alineación de puntos } \\
\text { clave (nube de puntos } \\
\text { dispersa) }\end{array}$ & Alta \\
\hline & Nube de puntos densa & Media \\
\hline & Malla & $\begin{array}{c}\text { Creada por: mapas de } \\
\text { profundidad } \\
\text { Media }\end{array}$ \\
\hline
\end{tabular}

Elaboración propia.

\section{DISCUSIÓN DE RESULTADOS}

La obtención del modelo fotogramétrico final del complejo estructural CE-03, así como de su ortomosaico, consta de un total de 192 capturas realizadas, por lo que su procesado, tanto en toma de fotos como en el postproceso en Agisoft Metashape, ha sido más largo con respecto a otros modelos.

Para comenzar a hablar sobre los resultados obtenidos, hemos de tener muy presente el flujo de trabajo que utiliza el sistema, y que ha sido comentado con anterioridad. Aunque los parámetros de ajustes de calidad, para el modelo final obtenido, se han realizado a calidad Media tanto en la realización de la Nube de Puntos Densa como en la elaboración de la Malla, se han llevado a cabo diferentes pruebas en el primero de los parámetros para comprobar la idoneidad del modelo finalmente obtenido. Por ello, entendemos que es necesario realizar una justificación de tal elección, ya que el software Agisoft Metashape ofrece calidades «extra altas», que, en primera instancia, podría entenderse como la calidad deseable en cualquier trabajo fotogramétrico, incluidos los del ámbito arqueológico, pero que, sin embargo, para la operatividad y rentabilidad de la documentación arqueológica ha resultado descartado.

Así, vamos a ofrecer una recopilación y análisis de los procesos realizados, desde una calidad muy baja (Mínima) hasta una calidad muy alta (Extra Alta). Hay que tener en cuenta que la capacidad de establecer parámetros altos o extra altos también viene determinada, no sólo por los intereses del trabajo que queramos llevar a cabo, sino por la propia capacidad de rendimiento de nuestro ordenador (potencia del hardware) y los componentes que contenga. Las características del equipo informático serán determinantes en el tiempo de procesado, así como en 
la calidad de los modelos que se originen con cada combinación de parámetros utilizados. Es este otro de los pasos críticos en el procesado de modelos fotogramétricos, ya que, como veremos más adelante, tuvimos problemas con nuestros equipos informáticos a la hora de realizar modelos en calidades altas.

El proceso más largo de toda la realización de un modelo fotogramétrico es la creación de la nube de punto densa, el primer paso después de la alineación de fotografías. La duración del mismo depende, obviamente, de la calidad que seleccionemos, yendo así desde los 7 minutos 54 segundos, en calidad Mínima, hasta las 19 horas, en calidad Alta.

Tras el análisis de cada uno de los modelos, y atendiendo a nuestro objetivo, que era obtener la suficiente claridad y nitidez que nos permitiese acometer el dibujo arqueológico sobre los modelos obtenidos, pudimos observar que la nube de puntos densa no presentaba grandes diferencias entre las calidades; se podía apreciar cómo el número de puntos era mayor, pero en general, la precisión que ofrecían era muy similar. Esto, sin embargo, no pasa con la creación de la malla donde, a diferencia del proceso anterior, se podían observar grandes diferencias cualitativas. Concretamente, la malla donde se podían apreciar más cambios en la calidad era en Mínima y Baja, que ofrecían una visión muy pobre y borrosa. La clara diferencia se puede apreciar en la malla de sombreado de calidad Media que sí ofrecía una mayor precisión y definición en los detalles. Por ejemplo, en esta malla con sombreado podíamos observar una notable diferencia en la apreciación del pavimento (Fig. 9). Sin embargo, la imagen que nos ofrecía la malla con procesado en calidad Alta con respecto a la de calidad Media no mostraba diferencias tan relevantes, para nuestro objetivo, como para decidirnos por su selección.

Llegados a este punto, es necesario transmitir los incidentes que tuvimos a lo largo de la generación del modelo en calidad Alta. El equipo con el que realizamos la mayoría de los modelos, a excepción del modelo en calidad alta, se trataba de un dispositivo portátil de 64 bits, con una memoria RAM de 16 GB y una tarjeta gráfica NVIDIA GeForce GTX 1060 6GB. Con este equipo creamos todos los modelos (a excepción, como hemos dicho, del modelo en Alta), con el objetivo inicial de determinar las posibilidades del software con respecto a la relación calidad-duración de los modelos procesados, que permitiría evaluar la rentabilidad de cada uno de ellos para nuestros intereses (tabla 2). De esta forma, con el equipo antes comentado, la creación de la nube de puntos densa en calidad Alta se realizó en unas 5 horas, mientras que la malla, tras llevar 4 horas procesándose, ocasionó un fallo crítico en el sistema, aún desconocido, que averió el equipo de manera irrecuperable. 


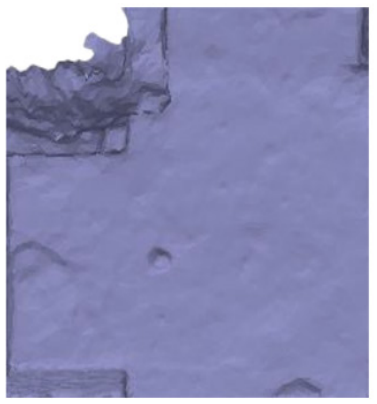

Calidad mínima

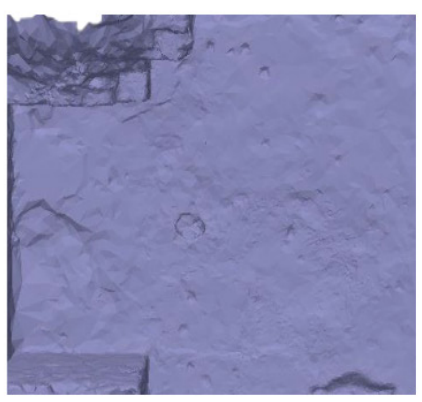

Calidad Baja

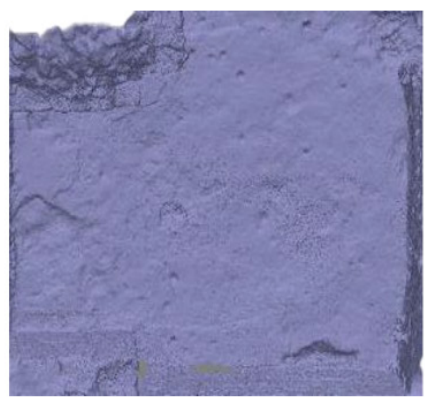

Calidad media

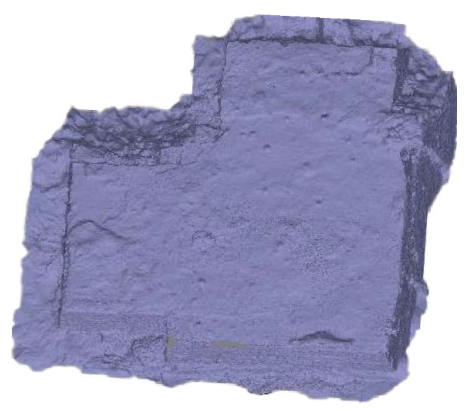

Calidad alta

Figura 9. Comparación de las cuatro mallas con sombreado. Elaboración propia.

TABLA 2

Tiempo de procesado en cada una de las calidades

\begin{tabular}{|c|c|c|c|c|c|c|}
\hline CALIDAD & $\begin{array}{c}\text { Alineación } \\
\text { de las } \\
\text { fotografías }\end{array}$ & $\begin{array}{l}\text { Nube de } \\
\text { puntos }\end{array}$ & $\begin{array}{l}\text { Creación } \\
\text { de malla }\end{array}$ & $\begin{array}{c}\text { Creación } \\
\text { de } \\
\text { texturas }\end{array}$ & $\begin{array}{l}\text { Creación de } \\
\text { ortomosaico }\end{array}$ & $\begin{array}{c}\text { Tiempo } \\
\text { total } \\
\text { invertido }\end{array}$ \\
\hline MÍNIMA & $1 \mathrm{~min} 10 \mathrm{~s}$ & $7 \min 54 \mathrm{~s}$ & $50 \mathrm{~s}$ & $8 \min 30 s$ & $6 \mathrm{~min} 50 \mathrm{~s}$ & $24 \min 94 \mathrm{~s}$ \\
\hline BAJA & $1 \mathrm{~min} 52 \mathrm{~s}$ & $\begin{array}{l}20 \mathrm{~min} \\
32 \mathrm{~s}\end{array}$ & $\begin{array}{c}18 \min \\
45 \mathrm{~s}\end{array}$ & $7 \min 30 s$ & $6 \min 24 \mathrm{~s}$ & $53 \mathrm{~min} 83 \mathrm{~s}$ \\
\hline MEDIA & $14 \mathrm{~min}$ & $\begin{array}{c}1 \mathrm{~h} 48 \\
\min \end{array}$ & $\begin{array}{c}1 \mathrm{~h} 30 \\
\min \end{array}$ & $\begin{array}{l}13 \text { min } \\
37 \mathrm{~s}\end{array}$ & $5 \min 02 \mathrm{~s}$ & $\begin{array}{c}3 \mathrm{~h} 35 \mathrm{~min} \\
39 \mathrm{~s}\end{array}$ \\
\hline ALTA & $20 \mathrm{~min} 20 \mathrm{~s}$ & $\begin{array}{c}19 \mathrm{~h} 13 \\
\min \end{array}$ & $\begin{array}{c}49 \mathrm{~min} \\
40 \mathrm{~s}\end{array}$ & 11 min & $4 \min 35 s$ & $20 \mathrm{~h} 13 \mathrm{~min}$ \\
\hline
\end{tabular}

Elaboración propia. 
Por tanto, probamos, otra vez, a realizar el mismo modelo de calidad Alta en otro dispositivo, en este caso, con un equipo de sobremesa de 64 bits, 32 GB de RAM y una tarjeta gráfica NVIDIA Quadro K2000D 2GB. Este equipo realizó la nube de puntos densa en 19 horas, las cuales se distribuyeron en 10 horas para la creación de los mapas de profundidad y 9 horas para la generación de la nube de puntos densa. De esta forma, una vez creada ésta y siendo conscientes de la tardanza del proceso, comenzamos la realización de la malla. Después de 8 horas de procesado, nos percatamos de un fallo en el modelo, avisándonos el software de la incapacidad de la realización de este proceso por un fallo de memoria. Es decir, tampoco este equipo tenía suficiente capacidad para procesar el modelo en esa calidad.

Tras intentarlo nuevamente, y obtener el mismo resultado, nos vimos obligados a utilizar un tercer equipo informático de sobremesa, con un procesador de 64 bits, 16 GB de RAM y una tarjeta gráfica NVIDIA Gforce RTX 2070 8GB. En su caso, y debido a la gran calidad del equipo, y teniendo ya realizada la nube de puntos densa, realizó la malla en 49 minutos, y el resto de procesos en un tiempo óptimo.

Aunque el software, como hemos comentado en el apartado anterior, ofrece la posibilidad de realizar modelos en calidades Extra Altas, en nuestro caso, cuando nos dispusimos a hacerlo con el último dispositivo expuesto (64 bits, 16 GB de RAM y tarjeta gráfica NVIDIA Gforce RTX 2070 8GB), obtuvimos que, tras la orientación de las fotografías, la realización de la restitución fotogramétrica se elevaba a unas 24 horas de procesado constante del equipo. Ello, unido al precio del mismo, que supone un desembolso económico muy importante, que no está al alcance de todo el mundo, hizo que considerásemos el modelo resultante con estas características, poco rentable. Por esto, es necesario que realicemos la oportuna reflexión al respecto de si, para nuestro trabajo como arqueólogos, nos resulta útil este tipo de modelos en tan alta calidad, ya que, al precio de los equipos necesarios para su procesado así como a la enorme duración temporal del mismo, debemos unir el hecho de no proporcionar un aumento en el detalle del modelo tan diferente al ofrecido por los modelos elaborados con las calidades inmediatamente por debajo, de tal modo que sea un criterio determinante para decidir su preeminencia sobre aquellos otros. Tras tener en cuenta estos aspectos, haber realizado pruebas con todas las calidades y observar los distintos inconvenientes que se presentaron, podemos, ahora sí, justificar por qué nos hemos decantado por la calidad media en nuestros modelos.

Como hemos expresado en el apartado anterior, podemos observar que las diferencias de la calidad de malla y textura entre las opciones Media y Alta son mínimas. Por lo que, para ajustar las características más convenientes para nuestro caso de estudio, se tienen que analizar otros parámetros más allá del de la calidad. Otro de los factores que determinará nuestra elección es el tiempo de procesado del modelo. Para la realización del modelo final, hemos tenido serios problemas, tanto con el equipo con el que estábamos trabajando como con la duración del procesado. Hay que tener en cuenta el tipo de dispositivo del que disponemos para elaborar los modelos, ya que no siempre se puede tener acceso a equipos potentes de sobremesa. En el caso de una excavación, el procesamiento de estos modelos poco después de la toma de datos hace que no siempre puedas acceder a estos equipos y que, en su lugar, sustituyas éstos por dispositivos portátiles que, aunque estando preparados con tarjetas gráficas, memorias y procesadores de 
calidad, presentan más fallos e incluso pueden acabar sufriendo daños, fatales, como ha sido nuestro caso. Por esto, debemos de tener en cuenta siempre nuestras posibilidades logísticas, ya que si queremos obtener restituciones fotogramétricas de calidades Alta y Extra Alta, debemos disponer del equipo adecuado, así como del tiempo suficiente (que en la mayoría de intervenciones arqueológicas, relacionadas con la llamada Arqueología Comercial o Pública, nunca se posee). Además, aun teniendo dispositivos potentes, la duración del procesado puede elevarse incluso a días, dependiendo también del tamaño y de la cantidad de capturas fotográficas realizadas. Por lo tanto, esta circunstancia también puede significar un punto clave para decantarse por calidades medias en el procesado. Hay que tener en cuenta, además, que en una actuación arqueológica el número de unidades identificadas puede ser muy alto, por lo que realizar modelos en calidades Alta o Extra Alta supone una cantidad de tiempo del que habitualmente no se dispone, y se puede optar, por tanto, por otros métodos que son, a priori, más lentos, pero que, atendiendo a dichas circunstancias, pueden resultar más ágiles que la fotogrametría con estas calidades, como es el caso del dibujo tradicional manual arqueológico (si bien, habrá que valorar si es asumible la pérdida de precisión del dibujo tradicional con respecto al dibujo a partir del modelo fotogramétrico).

Otro de los puntos a favor hacia las calidades medias viene determinado por el peso del modelo. Esto puede suponer que, a la hora de moverlo o modificarlo en otro tipo de software, como puede ser Blender, tengamos que acudir, previamente, a terceros programas para generar una retopología del modelo y reducir, de esta forma, su tamaño o la triangulación, es decir, la geometría del mismo. Esto se puede realizar con programas como, por ejemplo, Instant Meshes o MeshLab. Aun así, el gran peso del modelo no solo no es útil para su posterior postprocesado en otros softwares, sino que puede generar también dificultades a la hora de su almacenamiento.

En resumen, en nuestro caso de estudio optamos por las calidades medias (Fig. 10) debido, principalmente, a que la calidad y precisión en el detalle que ofrece el modelo en cuanto a las necesidades de documentación gráfica que requiere la arqueología, es muy buena y, por otra parte, reduce, en gran medida, los posibles problemas que se pueden generar en el equipo, así como los posibles fallos que pueden surgir a lo largo del proceso, además de reducir el tiempo de procesado del modelo, que, sin duda, para un arqueólogo/a, es esencial. 


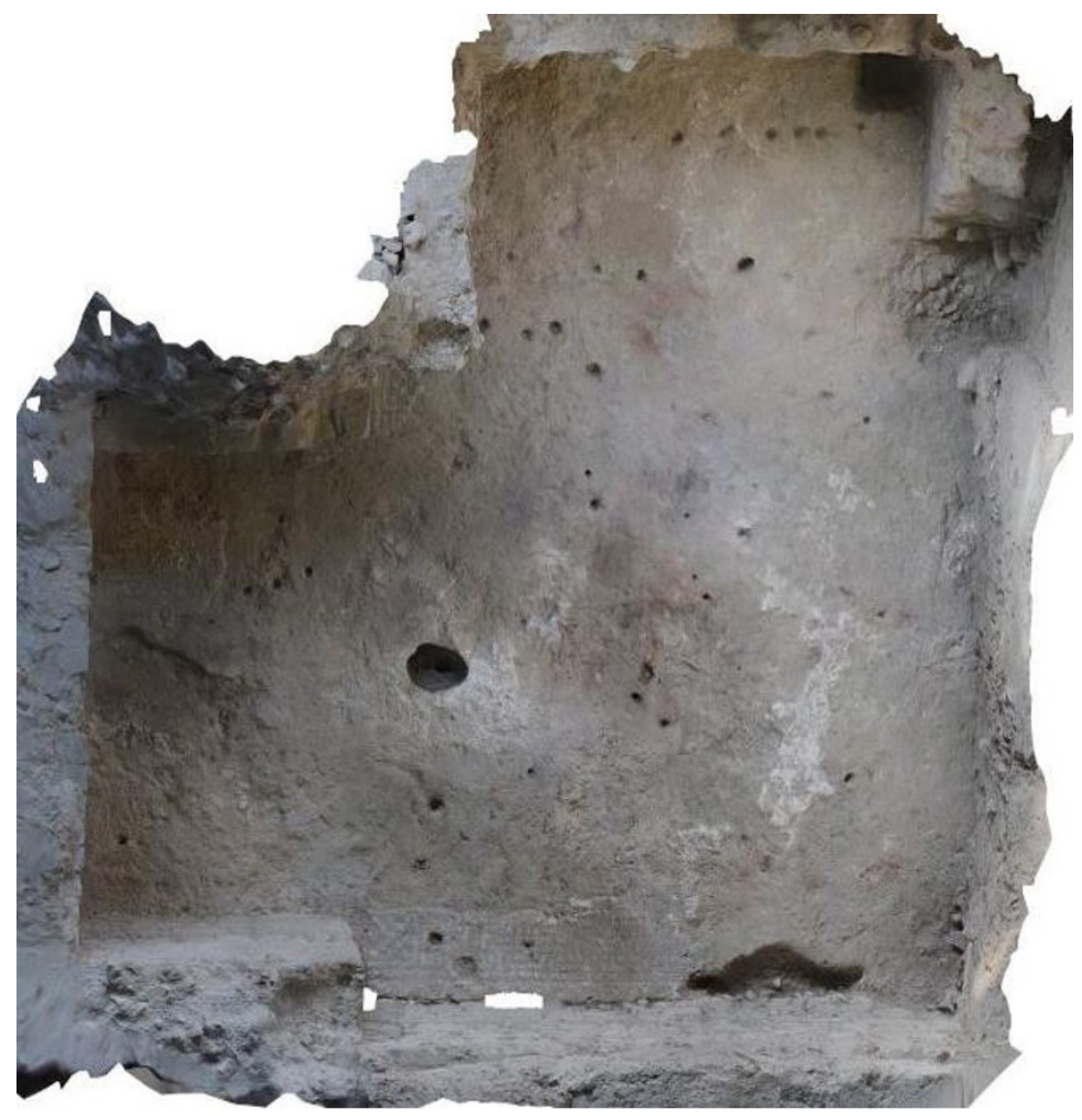

Figura 10. Ortofoto del Modelo Final. Calidad Media.

Una vez analizados los resultados y exponiendo el porqué de nuestra elección en los parámetros, es necesario que puntualicemos las ventajas y las desventajas que conlleva esta técnica de documentación gráfica en arqueología:

En cuanto a las ventajas hemos de tener en cuenta lo siguiente:

- Rapidez en la toma de datos.

- Precisión y posibilidad de efectuar levantamientos de alta precisión de un objeto, estructura, monumento, edificio o excavación, cualquiera que sea su dimensión, envergadura o complicación ornamental (GARCíA y MARRERO, 2009).

- Técnica de bajo coste, en determinadas circunstancias, debido a la versatilidad para hacer los modelos (cámara digital, smartphone).

- Es muy útil en la representación de texturas.

- La generación de ortomosaicos referenciados es otro de los puntos a favor 
dentro de la fotogrametría y, en concreto, de Agisoft Metashape.

- La calidad de detalle de los modelos es muy elevada, permitiéndonos por tanto que la documentación sea de gran calidad y precisión.

Por otro lado, en desventajas hay que anotar los siguientes aspectos:

- La calidad de los modelos depende de la toma de datos. Sin las suficientes capturas, y sin que éstas contengan el necesario solape, el software no podrá realizar una buena identificación ni orientación de las fotografías, por lo que el modelo será defectuoso.

- Aunque a la hora de tomar las fotografías podemos disponer, como hemos comentado anteriormente, de dispositivos asequibles, como smartphones, a la hora de procesar los modelos es importante contar con un equipo que tenga la potencia y capacidad suficiente para gestionar todo el procesado. Los problemas, principalmente, los encontramos cuando se exige un modelo de calidad Alta o Extra Alta, que contienen un número elevado de fotografías y que, por lo tanto, necesitan gran potencia por parte de nuestro equipo. Aunque los modelos en Mínima, Baja y Media calidad pueden ser asequibles para un dispositivo de gama media, hemos comprobado cómo en calidades superiores, "sufre mucho", los tiempos se dilatan en exceso o, directamente, el equipo no consigue llevar el modelo a su fin. Es un dato que hay que tener muy en cuenta a la hora de elegir la inversión en el equipo informático.

- Otro de los puntos que tenemos que tener en cuenta es el control de las luces durante la captura fotográfica. La toma de datos, como hemos dicho antes, es uno de los puntos clave, y de los que depende el modelo final. Y uno de los inconvenientes principales es el control de la luminosidad del espacio. Centrándonos en nuestro caso de estudio, este problema ha estado presente durante toda la fase de adquisición de tomas fotográficas, debido a la exposición al sol de ciertas partes del sondeo, a determinadas horas del día, y a la incapacidad de ocultarlo o mitigarlo debido a las características de la cubierta protectora del yacimiento.

Estos problemas de malla a causa de las diferencias de luminosidad, pueden ser solucionados mediante un proceso posterior, el postprocesado de modelos 3D fotogramétricos a través de herramientas como Blender, o durante la captura fotográfica, tomando las instantáneas cuando el sol no incidía directamente en el lugar de exposición (a primeras horas del día, al atardecer, etc.), lo cual genera otro problema, el de retrasar el ritmo de excavación, lo cual, no siempre es posible.

\section{CONCLUSIONES}

Es indudable la importancia que está adquiriendo la técnica de la fotogrametría digital para la documentación gráfica en arqueología. La razón principal para ello es, fundamentalmente, la excepcional calidad, en términos de detalles y precisión métrica, que ofrecen los modelos realizados mediante esta técnica, la rapidez de la toma de datos en campo, la multitud de vistas gráficas que se puede obtener a partir de dicho modelo, así como su, en líneas generales, bajo coste.

No obstante, es fundamental tener un buen conocimiento tanto de la técnica como de las características del programa de modelado $3 \mathrm{D}$ que se pretende utilizar, ya que de ello depende que nuestro trabajo sea rentable desde el punto de vista del tiempo invertido-resultados obtenidos. Debemos tener en cuenta 
que lo aparentemente mejor, elaborar el modelo a la mayor calidad que ofrece el programa, no siempre va a ser lo óptimo, es decir, lo más eficiente, por el consumo de recursos que supone. Se alcanza la eficiencia cuando se obtienen los mismos resultados (a nivel de calidad requerida) utilizando menos recursos (reduciendo tiempos y/o costes económicos). Es por ello que es básico planificar previamente, saber qué necesidades tienes y cómo utilizar los recursos que están a tu disposición, para optimizar el proceso y alcanzar los objetivos planteados al inicio.

En todo este proceso, uno de los aspectos más importantes, y que determinará la formación del modelo, es la captura o toma de datos en el yacimiento. Dicha captura se ha de realizar ajustando los parámetros de ISO, apertura y velocidad, así como asegurarnos del correcto solape de las fotografías para la posterior alineación de las mismas en el software. Es un paso crucial, pues una mala toma de datos lastrará de manera fatal el resultado final del modelo 3D generado.

Atendiendo a la variedad de calidades que permite Metashape, tras elaborar el modelo final de nuestro caso de estudio, el Complejo Estructural 03, con cada una de ellas (excepto la Extra Alta) y comprobar de manera minuciosa el resultado de los modelos generados, nos hemos decantado por la calidad Media por su enorme similitud con el de calidad Alta, que se ajusta a los intereses de detalle y precisión métrica que necesitamos en este caso, pero poseyendo como ventajas su peso más reducido y la considerable menor duración del procesado. Es muy probable que, en el ámbito de la documentación gráfica en Arqueología, podamos trabajar con dicha calidad como la más óptima, ya que permite maximizar los recursos a nuestra disposición (fundamentalmente, tiempo y coste económico) con un resultado ajustado a las necesidades de la praxis arqueológica.

Por último, sería conveniente cerrar las conclusiones con el necesario debate acerca de la sustitución, o no, por parte de las nuevas tecnologías, de las técnicas tradicionales de representación gráfica (dibujo arqueológico manual), o si, por el contrario, deberíamos realizar una alternancia entre ambas, argumentando, a favor de una $\mathrm{u}$ otra, a partir de parámetros como efectividad, rapidez $\mathrm{o}$ costes (MoyAnO, 2017). Es evidente que un modelo 3D generado a partir de la fotogrametría digital es más objetivo, más preciso desde el punto de vista métrico, así como su toma de datos es mucho más rápida en campo (si bien luego requiere de un procesado y postprocesado en laboratorio). No obstante, y en referencia a esa objetividad, tal y como ya indicase de manera muy lúcida el profesor Carandini, «El dibujo arqueológico no es una imagen más o menos realista de la realidad, sino una representación más o menos realista de la realidad interpretada en sus componentes y en las relaciones entre los mismos» (CARANDINI 1997: 116). Por tanto, la visión directa del objeto, cuando es dibujado por parte del propio arqueólogo, es fundamental en el proceso de interpretación de la secuencia arqueológica; y dicha observación, detenida y directa del original, no siempre se realiza cuando los procesos de registro de la secuencia están tan automatizados. Pero, además, pensamos que, en determinadas ocasiones, el uso de la técnica del dibujo arqueológico tradicional es complementario al proporcionado por esta técnica, ya que no siempre podrá ser aplicada atendiendo a la variada casuística de las actuaciones arqueológicas, fundamentalmente, aquellas del ámbito de la llamada Arqueología Comercial. No obstante, el continuo avance de este tipo de técnicas, que redunda en una mayor facilidad de uso y un coste cada vez menor (la utilización de productos de software libre puede democratizar el acceso 
universal a esta tecnología, si bien aún no alcanzan la operatividad y facilidad de uso de los productos de pago) es posible que permita, en un futuro cercano, restar el peso que aún hoy día mantiene el conocimiento del dibujo tradicional en la documentación gráfica de las intervenciones arqueológicas.

\section{REFERENCIAS}

Aparicio, P.; Espinosa-Figueroa, F.; MejíA, P., JARA, C. (2017): «Fotogrametría digital para el levantamiento 3D del sitio arqueológico de Todos Santos, Cuenca (Ecuador)», Estoa 7 (13): 25-34.

Angas PajAs, J. (2019): «Documentación geométrica del patrimonio cultural. Análisis de las técnicas, ensayos y nuevas perspectivas», Caesaraugusta, 86: 23-218.

CARAndini, A. (1997): Historias en la tierra. Manual de excavación arqueológica, Crítica, Barcelona

Cerezo Media, A.; Guevara Plaza, A. (2015): «El papel estratégico de las tecnologías de la información y las comunicaciones en el turismo», International Journal of Information Systems and Software Engineering for Big Companies, 2 (2): 52-67.

Charquero Ballester, A. (2016): «Prácticas y usos de la fotogrametría digital en arqueología», Dama. Documentos de Arqueología y Patrimonio Histórico, 1: 139157.

García Navarro, M.; Marrero Sosa, Ma .G. (2009): «Aplicación de la fotogrametría a la excavación arqueológica: Caserones-99», en Actas del XV Coloquio de Historia Canario-Americana, Cabildo de Gran Canaria, Las Palmas de Gran Canaria: 2161-2176.

GonzÁlez Martín, C.; El Amrani PaAzA, T. (2013): Guía Arqueológica. Villa romana de Salar, Diputación de Granada, Granada.

Maldonado Ruiz, A. (2019): La Aplicación de la Fotogrametría (SFM) y las Nuevas Tecnologías para la Mejora de la Documentación, Difusión y Divulgación del Patrimonio Arqueológico, Tesis Doctoral, Universidad de Granada.

MoyANO, G. (2017): «Eluso de la fotogrametría digital como registro complementario en arqueología. Alcances de la técnica y casos de aplicación», Comechingonia, 21 (2): 333-351.

Fernández García, Mª .I.; Román Punzón, J.M.; Moreno Alcaide, M.; Ruiz Montes, P.; Ramos Noguera, J. (2019): «Los mosaicos de la villa romana de Salar (Granada). Campañas de excavación de 2017 y 2018», en L. NeIRA JiméNEZ (ed.), Mosaicos romanos en el espacio rural. Investigación y puesta en valor, L'Erma di Bretschneider, Roma: 179-192.

López-Menchero Bendicho, V.M. (2011): «Propuesta para profundizar en La Carta de Londres y mejorar su aplicabilidad en el campo del patrimonio arqueológico», Virtual Archaeology Research, 2 (4): 65-69.

LópeZ-MENCHERO Bendicho, V.M.; GrANDE, A. (2011): «Hacia una Carta Internacional de Arqueología Virtual. El Borrador SEAV», Virtual Archaeology Research, 2 (4): 71-75.

Loza Azuaga, Ma.L.; Beltrán Fortes, J.; Román Punzón, J.M.; Ruiz Montes, P.; Moreno Alcaide, M.; Fernández García, Ma M. $^{\mathrm{a}}$ (2021): «The Roman villa of Salar (Granada). The sculptural program in archaeological context», Archivo Español de Arqueología, 94: e20. https:/ / doi.org/10.3989/aespa.094.021.20. 
Moreno Alcaide, M.; Román Punzón, J.M.; Ruiz Montes, P. (2019a): «Nuevo ejemplo del uso de tubi fittili en arquitectura hispanorromana: la sala abovedada de la villa romana de Salar (Granada)», en J. Coll CONESA (coord.), Opera Fictiles. Estudios Transversales sobre cerámicas antiguas de la Península Ibérica (Actas del IV Congreso Internacional de la SECAH-Ex Officina Hispana. Valencia, 26 al 28 de abril de 2017), Tomo II, La Ergástula Ediciones, Madrid: 503-516.

Moreno Alcaide, M.; Román Punzón, J. M.; Ruiz Montes, P. (2019b): «El uso de tubi fittili para cubiertas abovedadas en la hispania romana. Revisión bibliográfica y estado de la cuestión», SPAL. Revista de Prehistoria y Arqueología, 28 (1): 131156

Moreno Alcaide, M.; Román Punzón, J.M.; Ruiz Montes, P.; Ramos Noguera, J.; FERNÁNDEZ GARCÍA, Mª.I. (2021): "Arquitectura doméstica monumental en la Villa Romana de Salar (Granada)», en R.A. MARTínez, T. Nogales, T. e I. RodÀ (coords.), Actas del congreso internacional «Las Villas Romanas Bajoimperiales de Hispania», Diputación de Palencia, Palencia: 183-192.

Moreno Melgarejo, A.; Sariego López, I. (2017): «Relaciones entre Turismo y Arqueología: el Turismo Arqueológico, una tipología turística propia», Revista de Turismo y Patrimonio Cultural, 15 (1): 163-180.

Román Punzón, J. M.; Moreno Alcaide, M.; Ruiz Montes, P.; Ramos Noguera, J.; FERnÁndez García, Ma .I. (2021): «La decoración musiva y escultórica en la villa romana de Salar (Granada). Recientes hallazgos», en R.A. MARTínEZ, T. Nogales, T. e I. RodÀ (coords.), Actas del congreso internacional «Las Villas Romanas Bajoimperiales de Hispania», Diputación de Palencia, Palencia: 437446.

Schreibman, S.; Siemens, R.; Unsworth, J., eds. (2004): A Companion to Digital Humanities, Blackwell, Oxford.

Sociedad Española de Arqueología Virtual (2011): Los Principios de Sevilla. International Forum of Virtual Archaeology. 